\title{
Tratamento de melanoma oral em um cão com criocirurgia
}

\author{
Treatment of oral melanoma in a dog with cryosurgery \\ Marcelo Seixo de Brito e Silva', Liliana Borges de Menezes², \\ Tatyane Penha Sales ${ }^{3}$, Flávia Gontijo de Lima $^{3} \&$ Neusa Margarida Paulo 4
}

\begin{abstract}
RESUMO
O melanoma oral um dos tipos de câncer de pior prognóstico, com alta incidência de metástases. Raças como Cocker Spaniel, Boxer, Golden Retriever, Setter Irlandês são bastante acometidas. O tratamento preconizado é a maxilectomia parcial mas nem todos os proprietários concordam com tal procedimento. Assim, o tratamento alternativo com a criocirurgia tem sido usado, com resultados encorajadores. $\mathrm{O}$ presente trabalho relata o caso de um animal portador de melanoma oral tratado com criocirurgia com resultado satisfatório no que diz respeito à melhoria da sua qualidade de vida.
\end{abstract}

Descritores: biópsia, maxila, tumor.

\section{ABSTRACT}

Oral melanoma is one of the types of cancer with the worst prognosis and with a high incidence of metastasis. The Cocker Spaniel, Boxer, Golden Retriever and Irish Setter breeds are the first victims of this disease. The recommended treatment is partial maxilectomia but not all woners agree to this procedure. Hence, an alternative treatment with criosurgery has been used, with encouraging results. This study describes the case of an animal with oral melanoma that was treated with cryosurgery, which resulted in an improved quality of life.

Key words: biopsy, jaw, tumor. 


\section{INTRODUÇÃO}

Dentre os tumores orais mais freqüentemente encontrados em cães e gatos o melanoma maligno representa a neoplasia orofaríngea mais comumente apontada por alguns estudos [1,2]. Este se origina a partir da transformação dos melanócitos, evoluindo desde o nevus benigno até a formação de um tumor invasivo e metastático. $\mathrm{O}$ tratamento de escolha para esta doença é a excisão cirúrgica com margem de segurança de ao menos $3 \mathrm{~cm}$. Após o tratamento, os animais apresentaram uma sobrevida de aproximadamente três meses [7].

A criocirurgia pode ser um tratamento alternativo diante da impossibilidade da ressecção cirúrgica. Consiste na destruição de das células anormais com um mínimo dano a área adjacente e ao tecido considerado normal [3,4]. Os antibióticos podem ou não ser utilizados dependendo do tecido congelado e da possibilidade de contaminação da área criotratada [3,5].

\section{RELATO DO CASO}

Cadela da raça Cocker Spaniel Inglês, de 8 anos de idade foi atendida por estar apresentando epistaxe, hematemese intermitente e aumento de volume de coloração escura e consistente à palpação na região maxilar esquerda na altura dos pré-molares superiores (Figuras 1 e 2). Notou-se ainda odor fétido. O proprietário não soube precisar o inicio do quadro. Foi realizada uma biópsia incisional e o material classificado como melanoma. O proprietário foi informado das opções clinicas e cirúrgicas de tratamento e não autorizou a maxilectomia parcial nem a quimioterapia. Escolheu a criocirurgia após ter sido devidamente esclarecido sobre esta possibilidade. Procedeu-se então ao congelamento da massa por sonda fechada plana com três

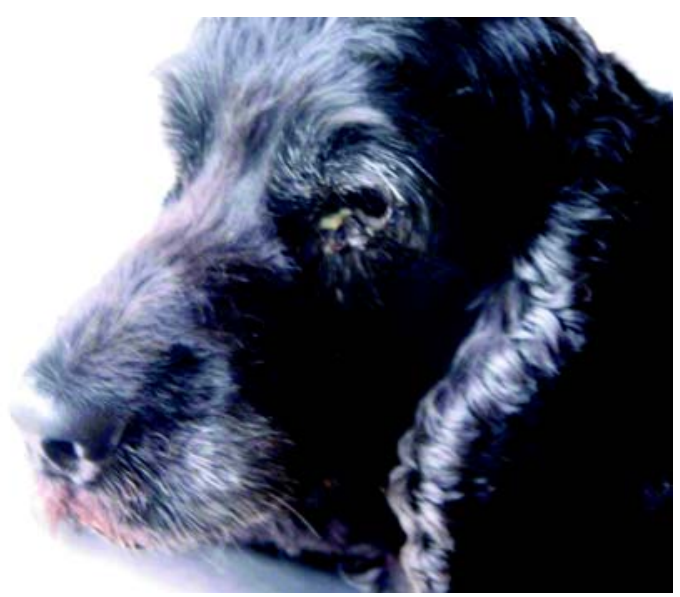

Figura 1. Cadela da raça Cocker Spaniel com melanoma oral. Notar aumento de volume. ciclos de congelamento por 2 minutos cada (Figura 3). Após 15 dias do tratamento o proprietário relatou satisfação com o tratamento e pode-se notar remissão da massa tumoral criotratada (Figura 4).

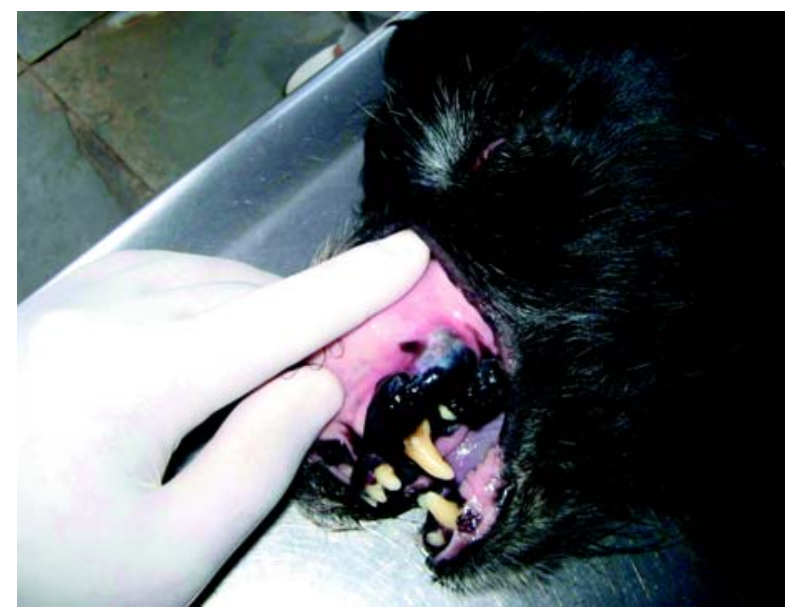

Figura 2. Aumento de volume escuro na região maxilar esquerda evidenciando o aspecto do melanoma na cavidade oral.

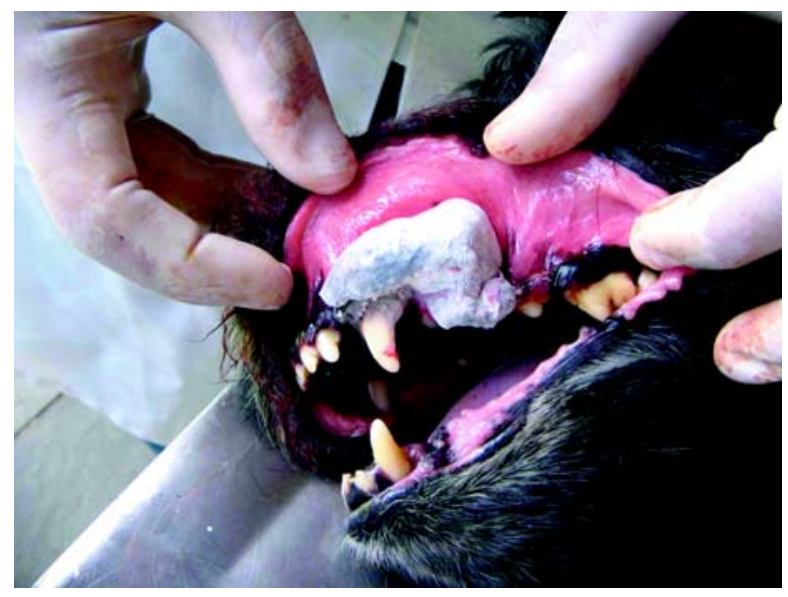

Figura 3. Melanoma oral durante o congelamento.

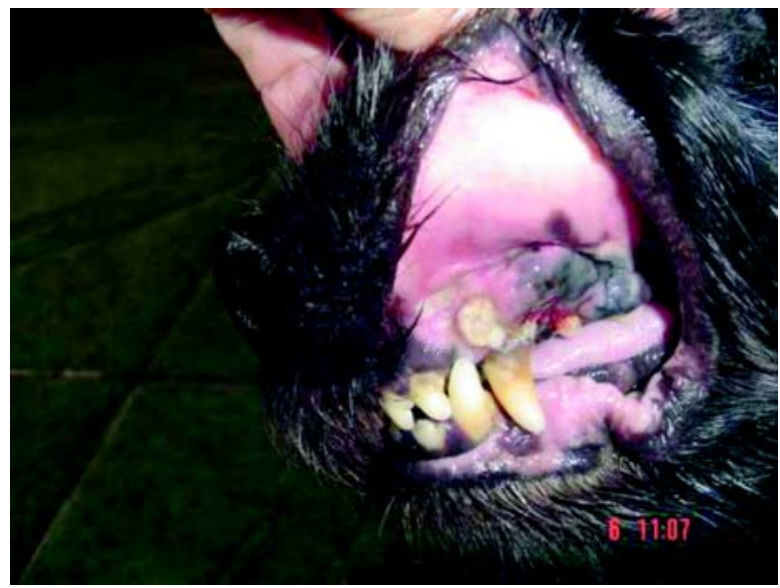

Figura 4. Aspecto da região maxilar esquerda 16 dias após a criocirurgia. 


\section{DISCUSSÃO E CONCLUSÃO}

A criocirurgia é uma técnica considerada segura por requerer planos superficiais de anestesia, ser pouco cruenta e por apresentar raras ocorrências de infecções secundárias para pacientes debilitados, idosos ou de risco. As cicatrizes são estéticas. Chama atenção ainda a possibilidade da sua utilização sobre lesões de difícil acesso como boca, região interdigital, reto e perineo. $\mathrm{O}$ animal tratado recuperou dos seus hábitos alimentares, ganhou de peso e reiniciou suas atividades físicas. Seis meses após a primeira criocirurgia o melanoma recidivou e durante o segundo tratamento foi identificada uma massa neoplásica na laringe que não pode ser abordada. $\mathrm{O}$ animal veio a óbito 3 meses após a segunda cirurgia, e no total a sobrevida do animal após o inicio do tratamento criocirurgico foi de 9 meses, tendo sido superior á média encontrada na literatura [7] com boa qualidade de vida, o que era o objetivo do tratamento.

\section{REFERÊNCIAS}

1 Couto C.G. 1992. Oncologia. In: Couto C.G. (Ed). Fundamentos de Medicina Interna de Pequenos Animais. Rio de Janeiro: Guanabara Koogan, pp. 897-906.

2 Damasceno A.D. \& Araújo E.G. 2004. Neoplasias orais em cães e gatos. In. Roza M.R.(Ed). Odontologia em pequenos animais. Rio de Janeiro: L. F. Livros de Veterinária, pp. 295-308.

3 Dawber R., Colver G. \& Jackson A. 1999. Criocirurgia Cutânea, principios e prática clínica. São Paulo: Manole, 135p.

4 Holberg D.L. 1998. Criocirurgia. In: Slater D.B. (Ed). Manual de Cirurgia de Pequenos Animais. São Paulo: Manole, pp. 237-243.

5 Lucas R. 1999. Crioterapia na clínica veterinária - avaliação da praticabilidade, exeqüibilidade e efetividade em dermatoses de caninos e felinos. 111f. São Paulo, SP. Dissertação (Mestrado em Clínica Veterinária) - Programa de Pós-graduação em Medicina Veterinária e Zootecnia, Universidade de São Paulo.

6 Radighieri R. \& Silva P.T.D. 2004. Melanocitoma Oral em Cão - Relato de Caso. In: X Congresso Paulista de Medicina Veterinária (Santos, Brasil). 1 CD-ROM. 